\title{
Monitoramento da Comunidade de Abelhas (Hymenoptera:Apidae) na Área de Influência Direta da Via Expressa Transolímpica
}

\author{
Cleber Vinicius Akita Vitorio.$~$ Josimar Ribeiro de Almeida $^{2}$ \\ \heliumcorp@heliumcorp.com.br
}

1. Helium Corporation Engenharia. Boa Esperança - Seropédica.

2. Universidade Estadual do Rio de Janeiro - UERJ

Histórico do Artigo:

Recebido em: 11 de abril de 2020

Aceito em: 12 de outubro de 2020

Publicado em: 30 de abril de 2021

Resumo: 0 objetivo deste trabalho foi avaliar a flutuação da comunidade de abelhas e realizar seu resgate, durante a fase de implantação dos $23 \mathrm{Km}$ da via expressa Ligação Transolímpica, também nomeada de corredor Presidente Tancredo de Almeida Neves (22 $\left.52^{\circ} 14.96^{\prime \prime} \mathrm{S} 43^{\circ} 24^{\prime} 36.77^{\prime \prime}\right)$ ). A comunidade de abelhas foi prospectada durante as atividades de implantação do empreendimento para as sazonalidades de inverno e primavera. As amostragens qualiquantitativas seguiram o protocolo padrão estabelecido na Resolução CONAMA No 346/2004 para abelhas nativas e africanizadas, sendo realizado o resgate de 34 enxames para a sazonalidade de inverno e 46 de primavera, donde a espécie mais abundante para as duas sazonalidades foi a Tetragonisca angustula, destaca-se que foi realizado o resgate da espécie Melipona quadrifasciata anthidioides, diversas espécies de abelhas do gênero Melipona encontram-se ameaçadas para os biomas Mata Atlântica e Cerrado.

Palavras-chave: Abelha-sem-ferrão, Transolímpica, Conservação da Biodiversidade, Entomologia Florestal.

\section{Monitoring the Bees Community (Hymenoptera: Apidae) in the Area of Direct Influence of the Expressway Transolímpica}

\begin{abstract}
The objective of this work was to evaluate the fluctuation of the bee community and to carry out its rescue, during the implementation phase of the $23 \mathrm{~km}$ of the Expressway Transolimpica also nominated corridor

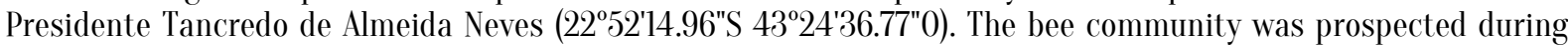
the project's implementation activities for winter and spring seasonality. Qualitative and quantitative samplings followed the standard protocol established in CONAMA Resolution $N^{0}$ 346/2004 for native and Africanized bees, 34 swarms were rescued for the winter season and 46 for the spring season, where the most abundant species for both seasons was the Tetragonisca angustula it is noteworthy that the rescue of the species Melipona quadrifasciata anthidioides was carried out, several species of bees of the genus Melipona are threatened for the Atlantic Forest and Cerrado biomes.

Keywords: Stingless Bee, Transolímpica, Biodiversity Conservation, Forest Entomology.

\section{Monitoreo de la Comunidad de Abejas (Hymenoptera: Apidae) en el Área de Influência Directa de la Autopista Transolímpica}

Resumen: El objetivo de este trabajo fue evaluar la fluctuación de la comunidad de abejas y llevar a cabo su rescate, durante la fase de implementación de los $23 \mathrm{~km}$ de la Autopista Transolímpica, también nominado corredor Presidente Tancredo de Almeida Neves (22 $\left.52^{\prime} 14.96^{\prime \prime S} 43^{\circ} 24^{\prime} 36.77^{\prime \prime} 0\right)$. La comunidad de abejas fue prospectada durante las actividades de implementación del proyecto para la estacionalidad de invierno y primavera. El muestreo cualitativo y cuantitativo siguió el protocolo estándar establecido en la Resolución CONAMA No 346/2004 para abejas nativas y africanizadas, Se rescataron 34 enjambres para la temporada de invierno y 46 para la temporada de primavera, donde la especie más abundante para ambas estaciones fue el Tetragonisca angustula, destaca que se realizó el rescate de la especie Melipona quadrifasciata anthidioides, Varias especies de abejas del género Melipona están amenazadas por los biomas del Mata Atlântica y del Cerrado.

Palabras clave: Abeja sin aguijón, Transolímpica, Conservación de la Biodiversidad, Entomología Forestal. 


\section{INTRODUÇÃo}

A Mata Atlântica é a formação natural mais antiga do Brasil, que existe há mais de 50 milhões de anos, surgindo no mesmo período que o soerguimento do sistema de montanhas da borda atlântica, existência do Oceano Atlântico e aumento gradual da temperatura do planeta. Hoje é uma das florestas mais biodiversas da Terra, com diferentes paisagens ao longo de sua extensão pela faixa litorânea do Brasil (FUNDAÇ̃̃o SOS MATA ATLÂNTICA, 2015). No entanto, mesmo ante 0 vasto processo histórico de desmatamento, o bioma Mata Atlântica contempla uma das maiores biodiversidades do planeta, onde são encontradas grandes concentrações de espécies endêmicas (SILVA et al., 2018) em elevado estágio de degradação. Com isto, pode-se considerá-lo como um hotspot, sendo a conservação de seus recursos naturais de suma importância para a humanidade.

Por ocuparem diversos hábitats e micro-habitats, os insetos ocupam lugar de destaque em diversas teias tróficas, sendo encontrados em diversas teias tróficas, assim oferecem uma gama de serviços ecossistêmicos, como notáveis transformadores dos ecossistemas e espécies mutualistas chave (SILVA et al., 2019; VITORI0 et al., 2019). Para ambos os serviços ecossistêmicos citados, destaca-se a ordem Hymenoptera, que é uma das quatro megaordens de insetos, paralelos com Diptera, Coleoptera e Lepidoptera. Somente dos Hymenoptera, são conhecidas cerca de 115.000 espécies, mas, segundo estimativas, podem existir de 600.000 a 1.200.000 espécies (SILVA et al., 2017).

0 papel das abelhas como agentes polinizadores eficientes é bem conhecido, inclusive para a agricultura moderna (LORENZON et al.,2018). Segundo Lorenzon \& Garcia (2003), as abelhas indígenas sem ferrão da região tropical têm sido dizimadas em velocidade mais rápida que as das florestas, por meio de queimadas, desmatamentos, predação, cultivos agrícolas, urbanização e poluição. Neste contexto, a relação mutualista é profundamente afetada se uma das espécies parceiras se perder, isto é, plantas angiospermáticas e abelhas possuem uma adaptação recíproca, fruto da coevolução que ocorreu entre plantas e abelhas desde os fins do Cretácio.

No entanto, o massivo crescimento do uso indiscriminado de agrotóxicos tem impactado populações de abelhas nativas e africanizadas no Brasil, de dezembro de 2018 até fevereiro de 2019, segundo o Castilhos (2019), cerca de mais de 500 milhões de abelhas foram encontradas mortas por apicultores apenas em quatro estados brasileiros, foram 400 milhões no Rio Grande do Sul, 7 milhões em São Paulo, 50 milhões em Santa Catarina e 45 milhões em Mato Grosso do 
Monitoramento da Comunidade de Abelhas (Hymenoptera:Apidae) na Área de Influência Direta da Via Expressa Transolímpica

Sul. De acordo com Castilhos (2019), foram calculados 770 milhões de abelhas mortas no Brasil no período de 2014 até 2018. Elas estavam contaminadas por neonicotinóides e pelo fipronil, que apareceu em 92\% das amostras de insetos. Como nem todos os apicultores registram as perdas, a estimativa é que o número real de insetos mortos passe de 1,5 bilhão.

0 Ministério da Agricultura publicou no Diário Oficial da União de 21 de maio de 2019, a autorização para comercialização de mais 31 agrotóxicos no Brasil. Dos 31 produtos, 13 foram avaliados como altamente ou extremamente tóxicos à saúde humana e 14 como muito ou altamente perigosos ao meio ambiente. Justificando a afirmação de Silva et al. (2011), que os governos de políticas e economia neoliberais são uma iminente ameaça a biodiversidade terrestre.

Paralelo ao risco toxicológico, as abelhas também enfrentam o aquecimento global, fragmentação de hábitat e a perda de diversidade florística, através da implantação de empreendimento imobiliários e industriais (SANTOS et al.,2018).

0 processo de colonização do Rio de Janeiro, começou em 1531, passando por diversos ciclos econômicos de exploração e de produção, no qual seus ecossistemas originais foram sendo progressivamente eliminados e descaracterizados. Como consequência, diversos animais característicos destes ambientes constam na Lista da Fauna Ameaçada do Estado do Rio de Janeiro, classificados em diferentes categorias de ameaça ou mesmo considerados extintos (BERGALL0 et al., 2000).

Durante a implantação das construções dos empreendimentos olímpicos, que ocorreu de 2012 até 2016, houve intensa supressão de vegetação na Mata Atlântica carioca. Paralelo à implantação dos empreendimentos imobiliários e industriais, existe a legislação ambiental que garante proteção as abelhas nativas e africanizadas, a Resolução CONAMA nº 346/2004, que assegura e visa a conservação das populações de abelhas nativas e naturalizadas aos ecossistemas associados com os biomas brasileiros.

A Construção da via expressa Ligação Transolímpica tem aproximadamente $23 \mathrm{~km}$, também chamada de corredor Presidente Tancredo de Almeida Neves. Esta via é uma concessão pública que liga os bairros de Recreio dos Bandeirantes, Barra da Tijuca, Curicica, Taquara, Jardim Sulacap, Magalhães Bastos, Vila Militar e Deodoro (MALHEIR0S et al., 2017). Uma vez que transpassa bairros com ecossistemas florestais bem estabelecidos, o manejo da fauna silvestre nestas áreas é imprescindível, incluindo também as abelhas.

Em atendimento a Resolução CONAMA No 346/2004, foi sintetizado o monitoramento da comunidade de abelhas nas áreas de influência da via expressa Ligação Transolímpica, tendo 
como objetivos deste trabalho: inventariar as espécies de abelhas existentes na área, avaliar a flutuação da comunidade nas estações de inverno e primavera, avaliar e mitigar os impactos negativos da construção do empreendimento em relação à comunidade de abelhas e reunir informações da história natural das espécies, incluindo hábitos alimentares, ameaças naturais e impactos antrópicos na área de influência.

\section{MATERIAL E MÉTODOS}

\section{Caracterização da Área de Estudo}

A área de estudo localiza-se na influência dos bairros de Recreio dos Bandeirantes, Barra da Tijuca, Curicica, Taquara, Jardim Sulacap, Magalhães Bastos, Vila Militar e Deodoro, sendo fronteiriça a unidade de conservação Parque Estadual da Pedra Branca (Figura 1).

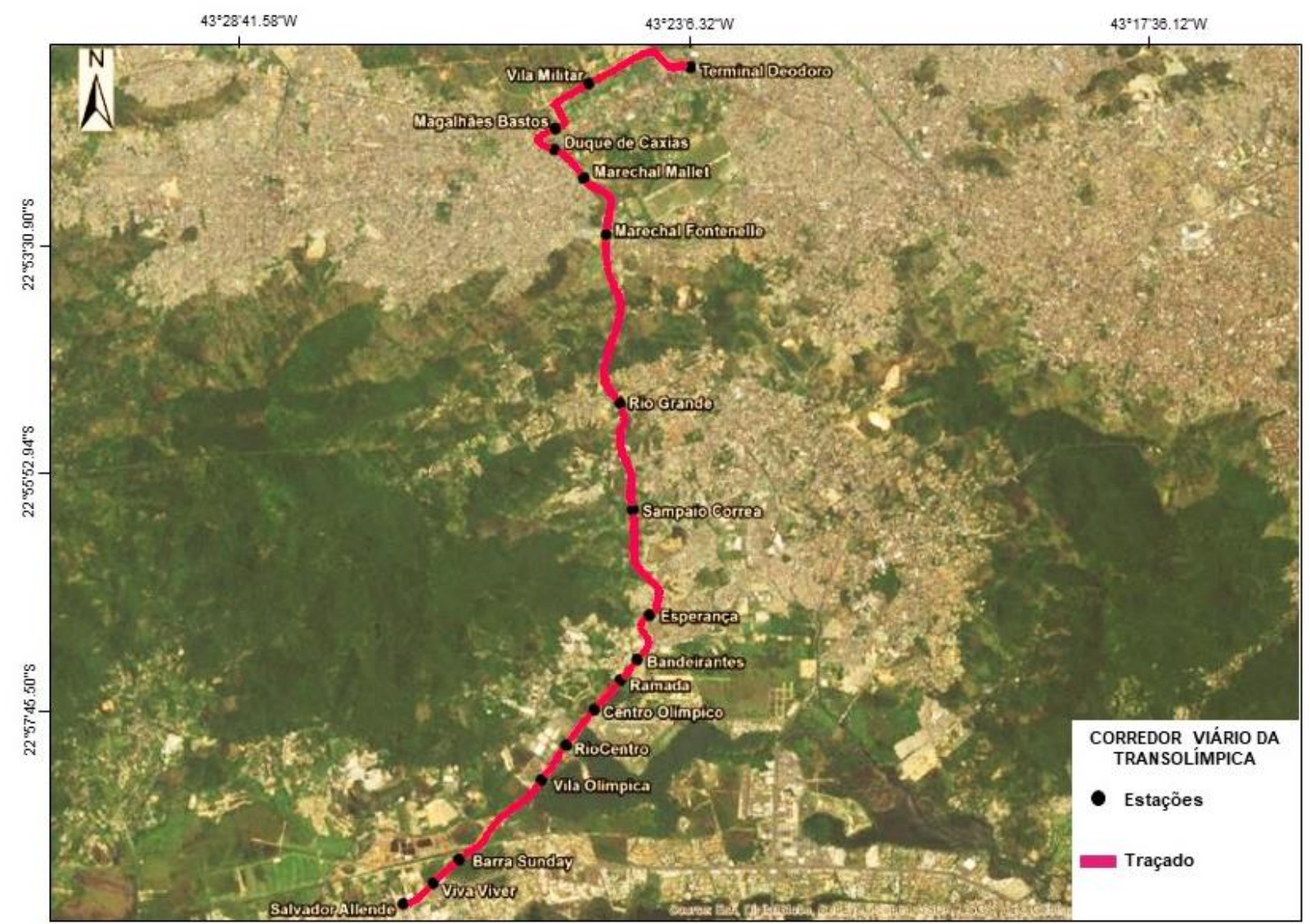

Figura 1. Mapa de localização do Corredor Viário da Transolímpica.

Fonte: do próprio autor.

De acordo com a Agência Nacional de Águas (ANA, 2020), o clima da região na qual o empreendimento está inserido é caracterizado por um clima tropical úmido, apresentando um microclima típico associado a uma região litorânea tropical. 0 maior índice pluviométrico e os 
Monitoramento da Comunidade de Abelhas (Hymenoptera:Apidae) na Área de Influência Direta da Via Expressa Transolímpica

maiores incrementos de temperaturas da região ocorrem durante o verão, ou seja, de dezembro a março, apresentando uma temperatura média de $30,80{ }^{\circ} \mathrm{C}$ e uma precipitação média de 121,50 $\mathrm{mm}$, enquanto os meses mais secos e menos quentes, correspondem ao período de maio a agosto, cuja temperatura média é de $26,25^{\circ} \mathrm{C}$ e a precipitação média de $59,75 \mathrm{~mm}$.

A vegetação geral do entorno é caracterizada por Floresta Ombrófila Densa Atlântica, também denominada Mata Atlântica sensu stricto (INEA, 2011) ou Floresta Pluvial Tropical (SILVA et al., 2019), com evidente fragmentação no ecossistema florestal em face das ocupações humanas e da implantação de empreendimentos imobiliários, como demonstrado na Figura 1.

\section{Delineamento Amostral e Análises}

Foram realizadas prospeç̧ões na área de influência direta do empreendimento Corredor Viário Transolímpica, isto é, vistorias paralelas até $250 \mathrm{~m}$ em torno do traçado do empreendimento. Foram realizadas duas campanhas estacionais, a primeira iniciada no solstício de inverno em 21 de junho de 2015, estendendo-se até 30 de julho de 2015 e a segunda prospecção iniciada no equinócio de primavera em 23 de setembro, estendendo-se até 01 de novembro de 2015.

Foram seguidas as respectivas etapas planejadas para o campo: adequação de equipamentos pelas questões de segurança; monitoramento para localização e identificação dos enxames de abelhas nativas e africanizadas; remoção dos enxames para caixas transportadoras; transporte dos enxames para área de refúgio; avaliação da recuperação dos enxames.

0 monitoramento de campo consistiu em buscas ativas de enxames de abelhas, foram prospectados os mais diversos hábitats e micro-habitats, para ocorrência de encontro dos sítios de nidificação, dos quais podemos apontar troncos de árvores vivas e mortas, barrancos e habitações humanas. Todos os enxames resgatados ocorreram no período vespertino para noturno, devido ao menor período de atividade das abelhas.

As caixas utilizadas para a remoção de abelhas nativas foram do modelo horizontal e 0 vertical (MARTINS et al., 2018). Neste estudo o modelo mais utilizado foi o vertical, por obedecer plenamente a autoecologia das espécies de abelhas nativas. No modelo vertical trabalhou-se com a divisória para ninho e melgueira, a adoção da caixa vertical deve-se a adequação com o padrão natural dos favos de cria nas árvores. Neste modelo, a parte inferior é destinada ao ninho e a superior de melgueira, para o depósito dos potes de alimentos. Antes de se iniciar a remoção, revestiu-se 0 interior da caixa com cera de abelha e própolis, que funciona como, isolante 
térmico, atrativo e facilitador de transferência do enxame, também foi realizado o alojamento da abelha rainha com a finalidade de restabelecer a população de abelhas na colmeia artificial.

A Apis mellifera possui um manejo simples, porém, demanda de cuidados e respeito às técnicas de segurança. Em campo, a transferência dos enxames foi feita com a introdução de iscas (caixa de papelão com atrativo a base de baunilha e óleo essencial de capim limão) para transferência dos enxames, isto em conjunto com o alojamento da abelha rainha com a finalidade de restabelecer a população de abelhas na colmeia artificial. Esse trabalho é de extrema importância para a segurança dos operários e das pessoas que vivem na área de influência direta do empreendimento, visto que durante a procura de um local para estabelecer a colmeia, as abelhas do gênero Apis ficam mais agressivas que o normal, devido à exposição a predadores e a falta de favos para preparar e estocar alimento. É uma condição adversa que deixa 0 animal em situação desconfortável, aumentando a possibilidade de ataques a animais maiores e ao ser humano. Após a captura do enxame, na caixa isca, utilizou-se a caixa de madeira no padrão Langstroth como padrão de colmeia artificial da população de abelhas do gênero Apis resgatadas. A caixa padrão Langstroth é feita de madeira, possui dez quadros também em madeira, utilizando arame fino número 24 para a fixação de favos (PASIN et al., 2014).

Um dos fatores utilizados como indicativo do tamanho do enxame foi o fluxo de abelhas nos tubos de entrada. Através do fluxo de abelhas na porta de entrada de uma colmeia é possível determinar se o enxame é abundante e suficiente forte para se manter na região recentemente degradada pelo mudança antrópica (PASIN et al., 2014). A área depositária ou de refúgio das espécies de abelhas nativas resgatadas da área de influência da via expressa Ligação Transolímpica foi a unidade de conservação Parque Estadual da Pedra Branca (2255'48.824"S; $\left.43^{\circ} 26^{\prime} 43.960 " W\right)$. No entanto, os enxames que se encontravam na zona de amortecimento da unidade de conservação foram mantidos, a zona de amortecimento do Parque Estadual da Pedra Branca foi utilizada como zona de quarentena para os enxames resgatados. Os enxames de Apis mellifera foram diligenciados para o Instituto de Zootecnia da Universidade Federal Rural do Rio de Janeiro, pois o Parque Estadual da Pedra Branca apenas recebe enxames de abelhas nativas.

No período de quarentena iniciou-se o monitoramento do vigor populacional dos enxames ao longo de um mês. As colmeias foram revisadas quinzenalmente para fazer o controle preventivo contra forídeos, além de outros predadores e oportunistas.

Foram fixados espécimes testemunhos, para todos os enxames encontrados, as abelhas coletadas foram postas em câmaras mortiferas com éter, posteriormente foram incluídas em 
Monitoramento da Comunidade de Abelhas (Hymenoptera:Apidae) na Área de Influência Direta da Via Expressa Transolímpica

coleções entomológicas, identificadas até o menor nível taxonômico possível com o uso das bibliografias da Coleção Entomológica Costa Lima (CECL), do Instituto de Biologia da Universidade Federal Rural do Rio de Janeiro (UFRRJ).

Foram plotadas curvas de acúmulo de espécies por estação em que ocorreu a coleta. Analisou-se a composição das espécies por meio de modelos multivariados, para facilitar e possibilitar o uso de variáveis relacionadas a espécies bioindicadoras.

Em relação ao número de espécimes coletados por campanha, devido às características intrínsecas do grupo estudado, dificilmente pode-se estimar a abundância populacional, visto que o critério utilizado foi a verificação do esforço de amostragem, e não pelo número obtido. A abundância populacional pode variar bastante sendo improvável que seja estimada para um local sem coleta prévia que se tenha referenciais de densidades da comunidade ecológica. Podese ter uma estimativa populacional após o primeiro ano. Os esforços de amostragem em Entomologia Ecológica trabalham com comparações probabilísticas de densidades e frequências, sendo os 'n' amostrados, dificilmente medidos em locais nunca amostrados ou registrados na literatura científica. Analisou-se o parâmetro Ecológico Frequência Relativa (FR), adaptando-o ao número médio de épocas de coleta, o qual é a porcentagem da ocorrência de enxames dos táxons, pela soma de ocorrências para todos os taxa do componente analisado. Portanto,

$\mathrm{F} 0=(0 \mathrm{ci} / \Sigma \mathrm{x} 1000 \mathrm{C})$

Para as épocas de coleta, os resultados encontrados para a frequência dos parâmetros foram essenciais para o devido uso das abelhas como ferramentas de avaliação da qualidade ecológica, ou seja, correlacionando a frequência dos taxa com sua autoecologia e impactos ambientais negativos levantados.

Índices biológicos devem ser sensíveis a uma gama de impactos biológicos, não apenas indicadores estreitos, uma vez que os atributos biológicos escolhidos como medidas devem ser capazes de discriminar os impactos causados pelo homem das variações de origem natural (temperatura, velocidade de corrente) (CRIST0 et al., 2019), de tal modo os resultados foram analisados de forma bidimensional, ao longo do tempo para cada semana de amostragem e de forma geral para toda a sazonalidade, com a finalidade de aferir possíveis impactos na comunidade de abelhas.

Neste estudo as comunidades foram descritas em função dos seguintes índices: 
0 Índice de Shannon (H’) é calculado por:

$\mathrm{H}^{\mathrm{ee}}=\Sigma \mathrm{pi}{ }^{*} \operatorname{Ln}(\mathrm{pi})$

onde pi corresponde à abundância relativa da espécie i (o fluxo de abelhas nos tubos de entrada foi tratado como uma medida da abundância), e Ln corresponde ao logaritmo natural.

0 Índice de Equabilidade de Pielou (J’) é derivado do índice de diversidade de Shannon, que representa a uniformidade da distribuição dos indivíduos entre as espécies existentes. Seu valor apresenta uma amplitude de 0 (uniformidade mínima) a 1 (uniformidade máxima). É calculado por:

$J^{\prime}=H^{\prime} / \ln (\mathrm{S})$

onde S corresponde à riqueza da amostra e H' ao índice de Shannon da mesma amostra.

As análises multivariadas objetivam reduzir o número de variáveis a poucas dimensões com o mínimo de perda de informação, permitindo a detecção dos principais padrões de similaridade e associação entre as unidades amostrais. A fim de compreender a similaridade entre os elementos encontrados, foi empregada também a análise de agrupamento (cluster) em função do ambiente amostral com base na matriz de similaridade e empregado o índice de BrayCurtis.

0 índice de Bray-Curtis varia de 0 a 1, com menores valores indicando amostras mais semelhantes. Essa padronização no intervalo entre um e zero facilita a interpretação e comparação. Os valores resultantes entre os pares de amostras das estações foram dispostos em uma matriz de similaridade. Esta matriz de similaridade foi submetida a uma análise de agrupamento, utilizando a ligação simples (Simple Link) como método de ligação. Para confecção das análises, foram usados os softwares estatísticos Past desenvolvido pela Taguchi \& Oonno (2005) e Microsoft Excel 2010.

\section{RESULTADOS E DISCUSSÃ0}

Foram inventariadas 10 espécies de abelhas (Tabela 1), segundo TEIXEIRA (2016), o estado do Rio de Janeiro é um dos melhores inventariados em abelhas nativas, apresentando 20 
Monitoramento da Comunidade de Abelhas (Hymenoptera:Apidae) na Área de Influência Direta da Via Expressa Transolímpica

espécies. 0 Jardim Botânico do Rio de Janeiro apresenta uma riqueza de 13 espécies de abelhas nativas, apenas 3 espécies a mais do que a diversidade encontrada neste estudo.

Tabela 1. Comunidade de abelhas resgatada para as sazonalidades de inverno e primavera.

Abundância absoluta de

\begin{tabular}{llll}
\multicolumn{1}{c}{ Espécie } & \multicolumn{1}{c}{ Topônimo } & \multicolumn{2}{c}{ enxames } \\
& & Inverno & Primavera \\
\hline Apis mellifera (Linnaeus, 1758) & abelha-africanizada & 6 & 4 \\
Trigona spinipes (Fabricius, 1793) & arapuá & 2 & 3 \\
Tetragona quadrangula (Lepeletier, 1836) & borá & 2 & 4 \\
Nannotrigona cf. testaceicornis (Lepeletier, 1836) & iraí & 2 & 3 \\
Tetragonisca angustula (Latreille, 1811) & jataí & 11 & 18 \\
Scaptotrigonaaff. postica (Latreille, 1807) & mandaguari & 3 & 5 \\
Melipona quadrifasciata anthidioides (Lepeletier, & mandaçaia & 2 & 3 \\
1836) & mirim & 2 & 2 \\
Plebeia droryana (Friese, 1900) & caga-fogo & 2 & 2 \\
Oxytrigona tataira (Smith, 1863) & tubuna & 2 & 2 \\
Scaptotrigona bipunctata (Lepeletier, 1836) & & & 3 \\
\hline
\end{tabular}

Fonte: do próprio autor.

Frente a diversidade semelhante com outros estudos para o estado do Rio de Janeiro, o protocolo de monitoramento proposto, mostrou-se adequado para o estudo da diversidade de apídeos na área do Corredor Viário da Transolímpica. A diversidade de abelhas nativas foi semelhante à anunciada no Parque Estadual da Pedra Branca que possui 9 espécies de abelhas (PENA \& BRANCO, 2017), mandaçaia (Melipona quadrisfaciata quadrisfaciata), uruçu amarela (Melipona rufiventris), guaraipo (Melipona bicolor bicolor), iraí (Nannotrigona testaceicornis), mirim (Plebeia droryana), jataí (Tetragonisca angustula), guiuruçu (Schwarziana quadripunctata), caga-fogo (Oxytrigona tataira tataira) e mandaguari (Scaptotrigona postica). No entanto este monitoramento inventariou 5 espécies de abelhas não registradas no Parque Estadual da Pedra Branca (tabela 1), o que reforça os estudos de Bergallo et al. (2000), de que mesmo em fragmentos florestais antropizados e descaracterizados da Mata Atlântica, é possível acessar uma biodiversidade considerável, o que reforça a necessidade de conservação deste bioma com alto nível de endemismo. 


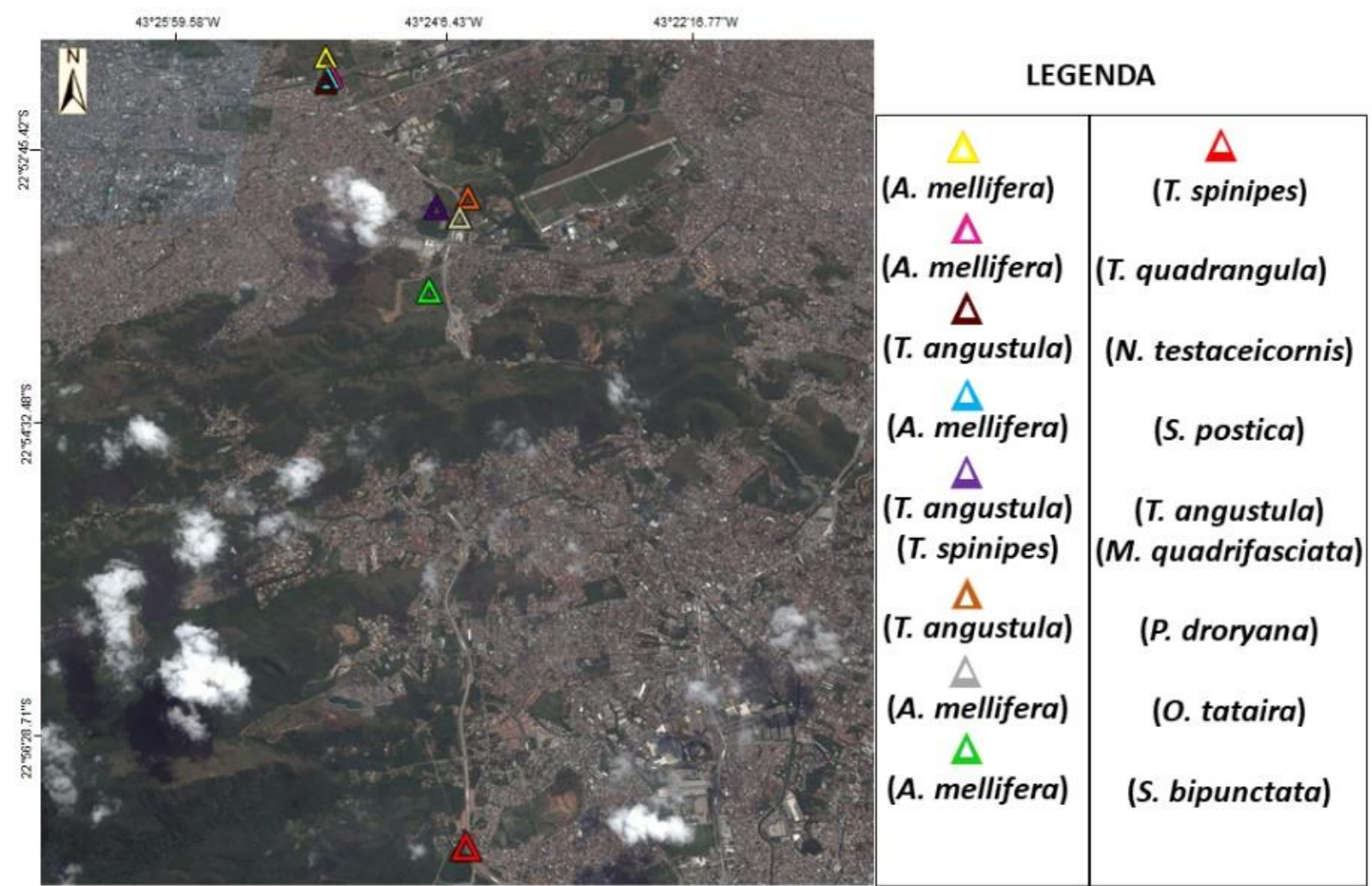

Figura 2. Georreferenciamento dos enxames encontrados no monitoramento de inverno. Fonte: do próprio autor.

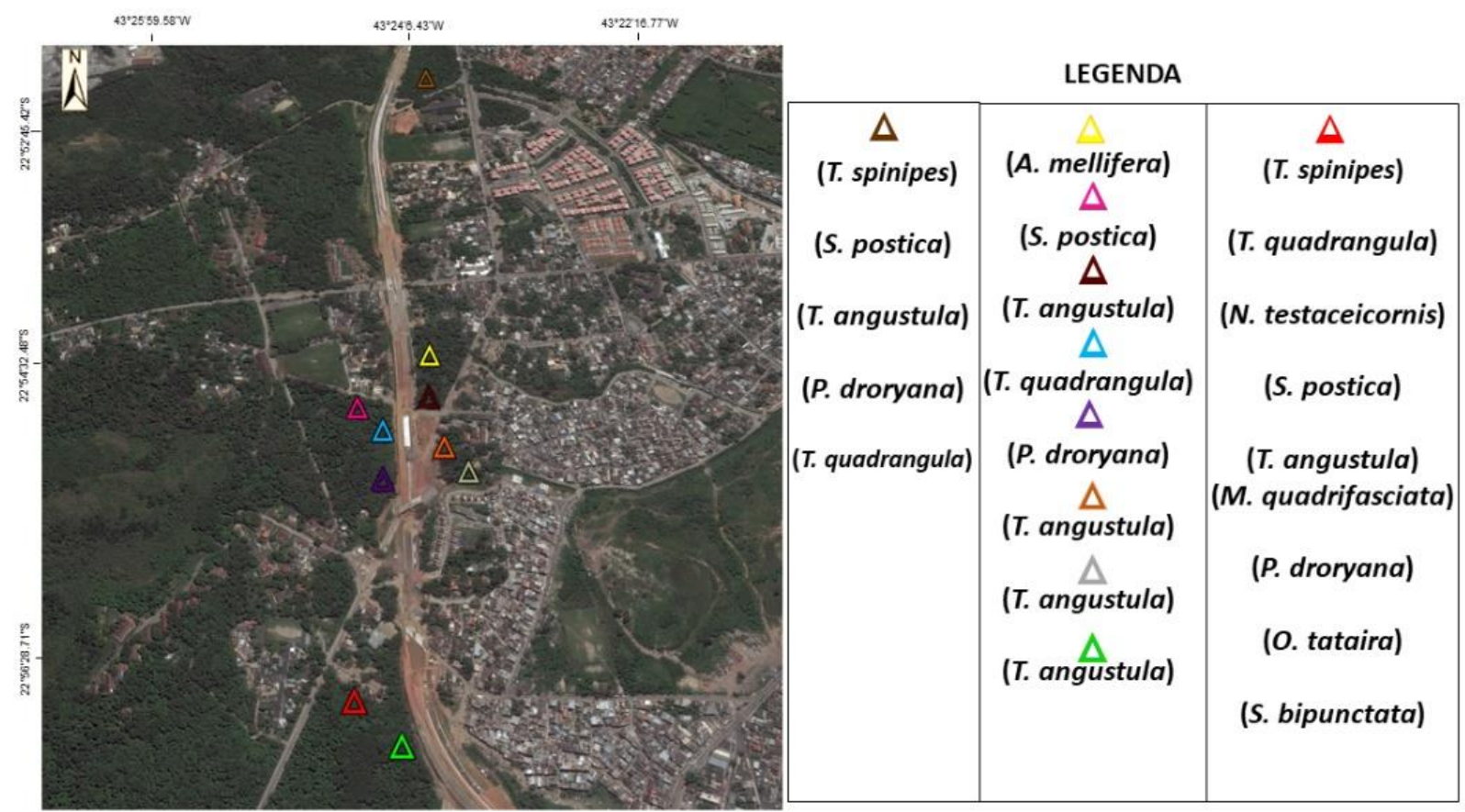

Figura 3. Georreferenciamento dos enxames encontrados no monitoramento de primavera. Fonte: do próprio autor.

Foram levantados 34 enxames durante a campanha invernal de monitoramento (Figura 2), com uma média de encontro de 3,4 enxames por semana e durante a campanha de 
Monitoramento da Comunidade de Abelhas (Hymenoptera:Apidae) na Área de Influência Direta da Via Expressa Transolímpica

monitoramento primaveril um contingente de 46 enxames, com uma média de 4,6 enxames por semana. A maior parte das ocorrências de enxames foram no bairro de Curicica do município do Rio de janeiro (RJ), isto é, na Colônia Juliano Moreira. Os demais locais desta área: Deodoro, Magalhães Bastos e Marechal Fontenelli (Figura 3).

Embora tenham se obtidos diversidades absolutas iguais em ambas sazonalidades, a flutuação das comunidades e seus pontos de encontro foram distintos, tanto no inverno quanto na primavera (Gráfico 1 e Gráfico 2). As abelhas são espécies mutualistas chave, agindo diretamente no serviço ecossistêmico da polinização, a fenologia reprodutiva das espécies vegetais da Mata Atlântica tende ao período do início da primavera, estendendo-se ao verão com a frutificação, estas sazonalidades permitem uma maior entrada de luz solar nos ecossistemas tropicais, aumentando a produtividade dos mesmos, o que resulta com a época da floração e da frutificação (WOLOWSKI et al., 2016). Outrossim, é importante ressaltar que tanto no Gráfico 1, quanto na Gráfico 2, a região identificada como Cl0, que é a mesma para ambas as figuras, é uma área rica e abundante em enxames de abelhas nativas, cuja proteção ocorre por parte da comunidade local e parte do Campus Fiocruz Mata Atlântica (CFMA), na área da Colônia Juliano Moreira, que exerce o serviço de educação ambiental na área.

Gráfico 1. Flutuação da comunidade de abelhas durante as obras do Corredor Viário da Transolímpica durante a sazonalidade invernal.

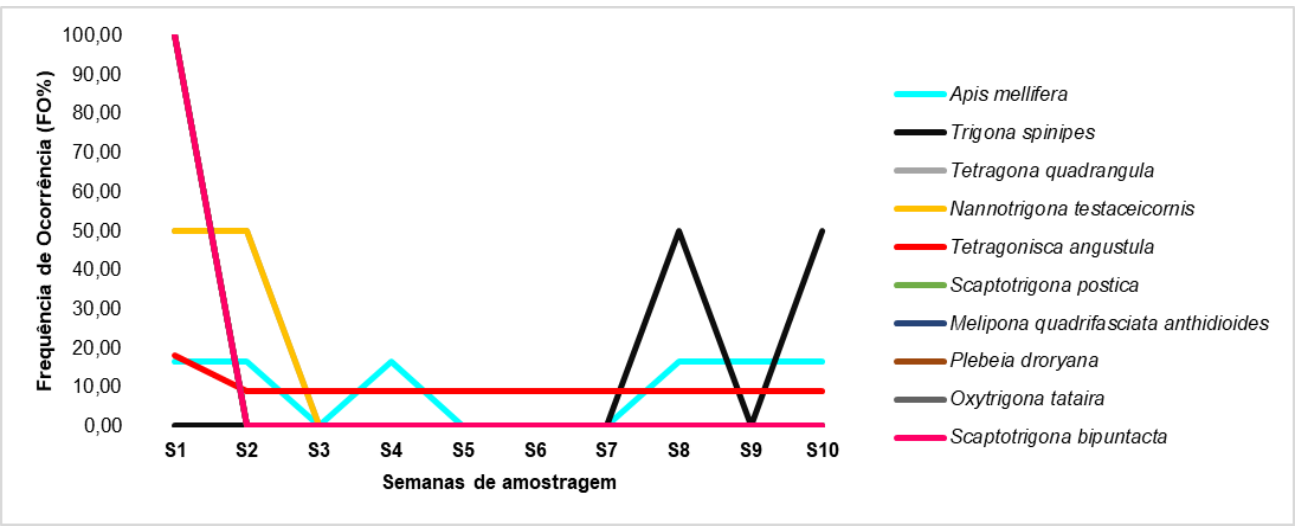

Fonte: do próprio autor.

A única espécie que apresentou ocorrências constantes durante todas as semanas de monitoramento na sazonalidade de inverno foi Tetragonisca angustula. A abelha africanizada Apis mellifera, não apresentou nenhuma ocorrência de enxame na quinta, sexta e sétima semana do inverno. Segundo Moura et al. (2014), o melhor nicho de atividade de A. mellifera ocorre a temperaturas de 15,48 e $31,09^{\circ} \mathrm{C}$ e umidade relativa do ar entre 43,13 e $92,70 \%$. Para o forrageamento de pólen, as temperaturas ideais são entre 15,48 e $27,61^{\circ} \mathrm{C}$, e a umidade relativa 
do ar ideal entre 45,00 e 89,50\%, embora a temperatura influencie na flutuação desta espécie, ela não é limitante a mesma, de tal modo que a partir da oitava semana a ocorrência de enxames desta espécie foi ocorrente.

A espécie T. angustula, é uma espécie de distribuição pantropical e provavelmente a abelha sem ferrão mais conhecida do Brasil. É uma espécie que se adapta bem a ambientes urbanos. Talvez seja a espécie mais criada racionalmente pela facilidade de adaptação em caixas e porque requer pouco espaço para a sua sociedade. Segundo Koffler \& Kleinert (2012), esta espécie não possui variações sazonais em sua sociedade sendo encontrada em todo ano adaptando-se a ambientes silvícolas, periurbanos, rurais e urbanos, é um espécie de grande potencial biótico, poucas exigências em sua colonização e de amplo forrageamento na busca de alimentos o que justifica ter sido a espécie com maior destaque em Frequência de ocorrência (F0\%) para este estudo, além da espécie com maior abundância de enxames (Gráfico 2).

Gráfico 2. Flutuação da comunidade de abelhas durante as obras do Corredor Viário da Transolímpica durante a sazonalidade primaveril.

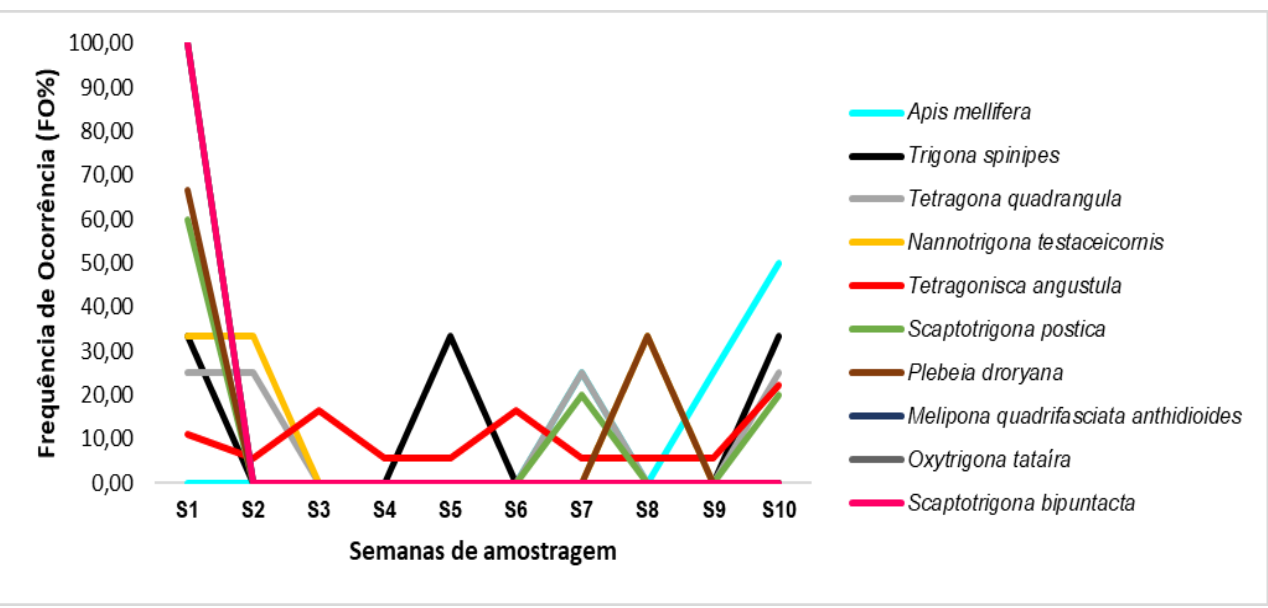

Fonte: do próprio autor.

Para a sazonalidade da primavera a única espécie que também apresentou ocorrências durante todas as semanas foi $T$. angustula. A espécie A. mellifera apresentou menores ocorrências e 3 de seus 4 enxames amostrados na primavera encontraram-se destruídos pela ação da própria população local, possivelmente por seu caráter altamente defensivo.

A espécie T. spinipes apresentou picos de ocorrências para o início, meados e final da primavera (Gráfico 2)., a qual é uma espécie agressiva e ladina, que invade enxames de outras espécie nativas em busca de alimento, gerando a destruição da colônia invadida (SILVA et al., 2017). Durante as atividades de monitoramento no início da primavera, foi possível observar esta espécie tentando ocupar uma colônia de Melipona quadrifasciata anthidioides, que foi 
Monitoramento da Comunidade de Abelhas (Hymenoptera:Apidae) na Área de Influência Direta da Via Expressa Transolímpica

resgatada e diligenciada ao Parque Estadual da Pedra Branca, destaca-se que diversas espécies do gênero Melipona encontram-se ameaçadas de extinção na região sudeste, sendo importante a sua conservação (NISHIO et al., 2012). No início da primavera muitas espécie nativas ainda se encontram enfraquecidas, sendo mais comum o ataque de T. spinipes nestes períodos. Além dos ataques a outras abelhas nativas, a T. spinipes destrói os botões florais de algumas plantas, para a síntese de seus ninhos, no processo utilizam fibras vegetais de flores maduras e jovens, podem ainda o fuste de árvores e sua resina destruindo seu floema, locais com abundância de enxames de T. spinipes, tendem a sofrer com a descaracterização florestal (SILVA et al., 2017).

A espécie Scaptotrigona postica, também apresentou ocorrências no início, nos meados e ao final da primavera (Gráfico 2), é uma espécie de ampla distribuição em território brasileiro, e com alto potencial biótico, se adaptando razoavelmente bem a ambientes periurbanos.

0 índice de diversidade de Shannon (H’) e a equitabilidade de Pielou (J'), apresentaram acréscimo do inverno para a primavera, isto é, mesmo que ambas as sazonalidades apresentaram diversidades absolutas iguais. A diversidade $H^{\prime}$ foi de 2,121 nat.ind ${ }^{-1}$ e uma equitabilidade de J' 0,9211 e para a primavera a diversidade H' de 2,173 nat.ind ${ }^{-1}$ e uma equitabilidade J' de 0,9436. Provavelmente em face de uma ocorrência de enxames mais distribuídos durante as semanas de monitoramento da primavera, resultaram em incrementos de diversidade para esta sazonalidade.

A resposta das espécies às flutuações ambientais depende de vários fatores, tais como sua biologia, grau de especialização por recursos e a presença de competidores (SILVA et al., 2019; VITORI0 et al., 2019). Consequentemente, as espécies de uma comunidade podem responder diferentemente a uma mesma flutuação ambiental. Em florestas neotropicais, aparentemente a atividade reprodutiva das espécies da entomofauna parece ser estimulada pelo término das chuvas, principalmente quando a oferta de alimento é alta (Silva et al., 2017).

A ordenação indireta das semanas de amostragem por análise de grupamento Cluster, resultou no gráfico da Figura 4. Para a análise dos grupos considerados, foi considerado o nível de $45 \%$ da maior similaridade relativa entre os terminais. A análise de agrupamento apresentou 6 grupos no nível de 45\% de similaridade, denominados A, B, C, D, E e F. 


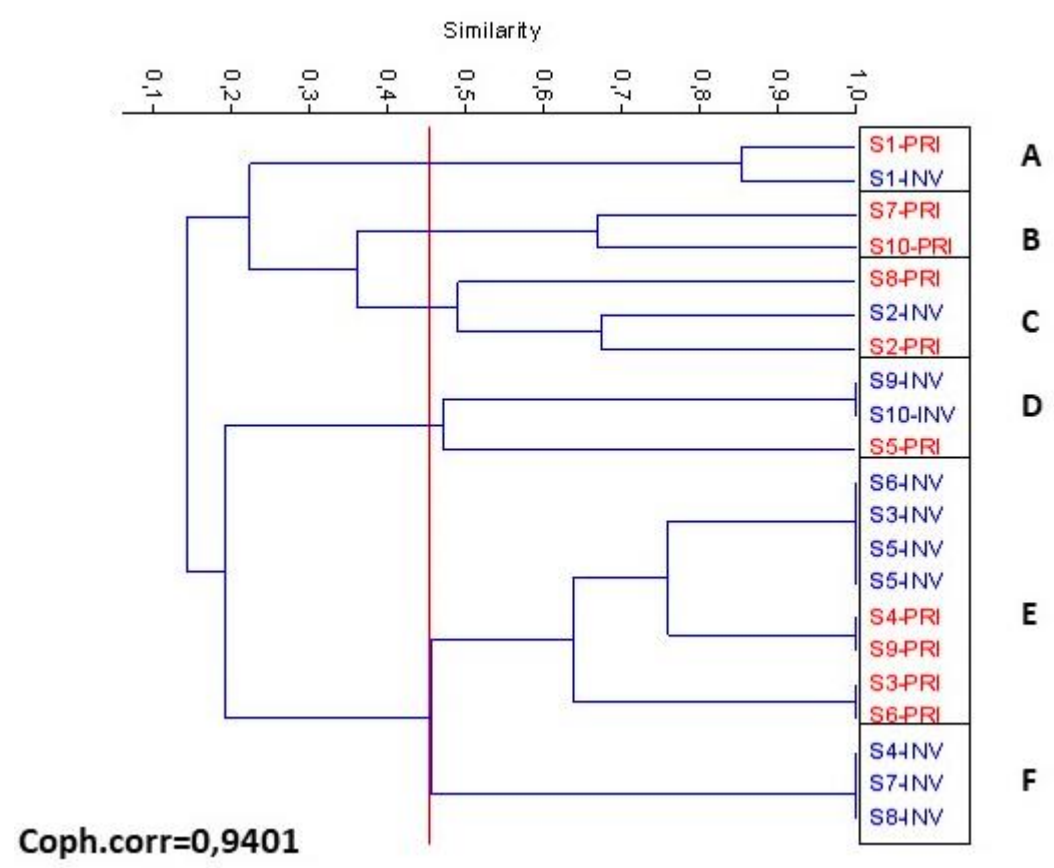

Figura 4. Análise de agrupamento entre as áreas amostrais para todas as sazonalidades. Legenda: S-semana de amostragem; Pri- primavera; Inv- inverno.

Fonte: do próprio autor.

0 grupo A foi o que apresentou a maior similaridade entre sazonalidades distintas, sendo representado pela ocorrências, abundâncias e diversidades da última semana de monitoramento de inverno e a primeira semana de monitoramento na primavera. As variáveis ambientais da primeira semana de primavera são influenciadas pelas variáveis da sazonalidade de inverno, refletindo diretamente na distribuição e diversidade das espécies de abelhas nativas. No grupo B não ocorreu nenhuma similaridade do monitoramento de primavera com semanas de monitoramento do inverno. A fenologia florestal do ambiente amostral que se encaminha para as influências da sazonalidade do verão, podem modificar a distribuição e ocorrência da comunidade de abelhas quanto a seu forrageamento e busca por abrigos. 0 grupo $\mathrm{C}$ apresentou uma similaridade de $50 \%$ entre a oitava semana do monitoramento de primavera com a segunda semana do monitoramento de inverno e a segunda semana do monitoramento de primavera. Foram consultados os dados do INMET para a estação automática da Vila Militar-RJ (INMET, 2019), uma vez que estas 3 semanas de monitoramento foram as que apresentaram maior pluviosidade, para estas semanas o pico de umidade relativa (\%) chegou a 100\%, igualando os níveis de dificuldade de encontro e ocorrência por enxames. Para o Grupo D foi necessária a conjunção de duas campanhas semanais de monitoramento de inverno para igualar a ocorrência, abundância e diversidade de uma campanha semanal de monitoramento de 
Monitoramento da Comunidade de Abelhas (Hymenoptera:Apidae) na Área de Influência Direta da Via Expressa Transolímpica

primavera. E para o Grupo E foram necessárias 4 semanas de monitoramento de inverno para obter-se à similaridade com duas campanhas semanais de primavera. 0 Grupo $\mathrm{F}$ foi representado pelos meados do monitoramento na sazonalidade do inverno, assim como o grupo $\mathrm{B}$ que possui características intrínsecas à primavera, 0 grupo $\mathrm{F}$ possui características intrínsecas à sazonalidade invernal, diferenciando-se consideravelmente das ocorrências, abundâncias e diversidades de enxames das campanhas semanais primaveris.

No Gráfico 3, estão dispostas as curvas de acumulação de espécies, que demonstram uma tendência de estabilização e com poucas diferenças entre a sazonalidade de inverno e de primavera, sugerindo que este monitoramento consolidou um inventário razoavelmente completo da comunidade de abelhas da área de influência do Corredor Viário Transolímpica e que poucas espécies tenderão a ser registradas com incremento do esforço.

Gráfico 3. Curva de acumulação de espécies. Cada semana para a sazonalidade de inverno (A) e primavera (B) correspondem a uma unidade amostral (10 semanas em 1 campanha $=10$ unidades amostrais).

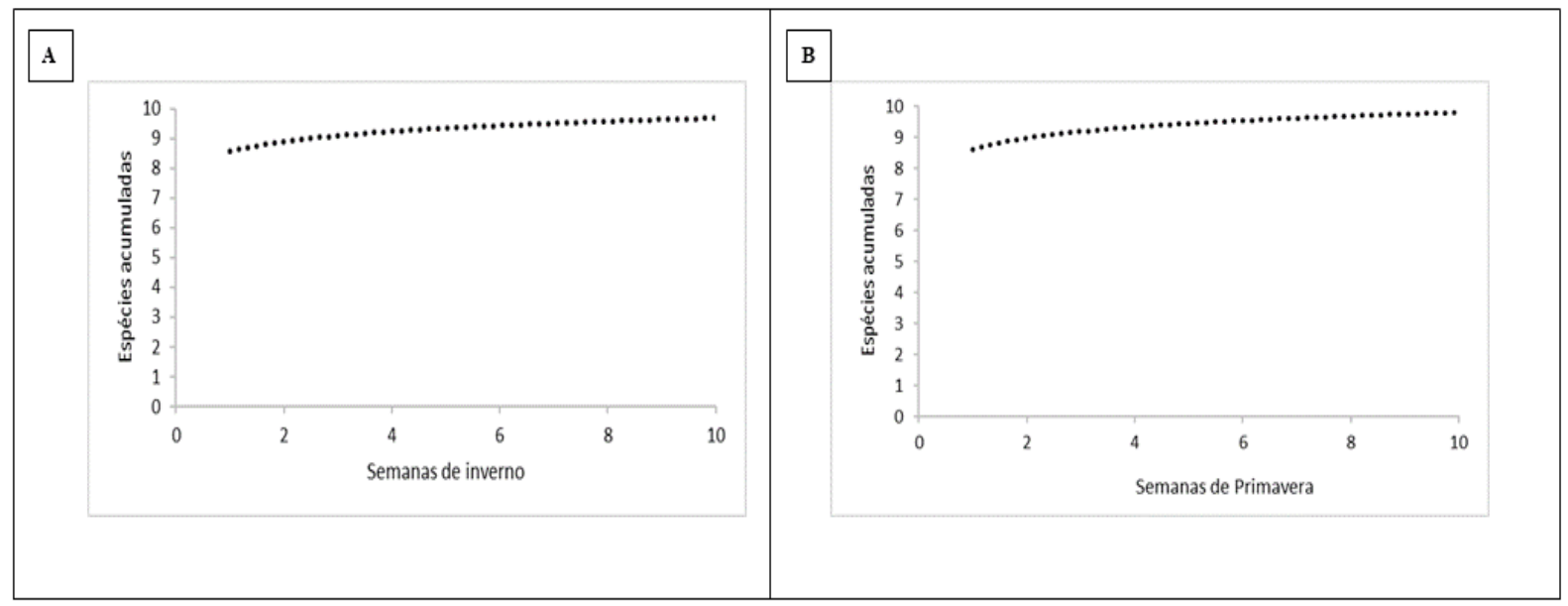

Fonte: do próprio autor.

\section{Impactos Ambientais e Realocação de Enxames}

Do ponto de vista da prestação de serviços ambientais as abelhas estão entre os seres vivos mais importantes dos ecossistemas terrestres, sendo cabal a sua conservação para o bem das gerações futuras e dos biomas. Paralelamente a esta importância, existe a necessidade da expansão urbana e industrial das civilizações modernas que estão sob o chicote dos primitivos sistemas sociais baseados em capital, assim um dos maiores desafios da humanidade, são o paradoxo em equilibrar a insana necessidade de acumular capital e a garantia da conservação do meio ambiente. Segundo Castilhos (2019), as abelhas enfrentam como maior risco a sua 
existência 0 aquecimento global, o desmatamento das florestas nativas em todo mundo e 0 uso indiscriminado de agrotóxicos liberados pelos governos neoliberais.

De forma categórica na área de influência do Corredor Viário Transolímpica, a comunidade de abelhas enfrenta como principais impactos negativos a sua existência (Figura 5):

1 - o desmatamento gerado pela implantação de empreendimentos imobiliários sem a compensação ambiental na mesma sub-bacia em que o desmatamento ocorreu, neste caso elegesse como compensação ambiental ideal a projetos de recuperação de áreas degradadas (PRAD) com o uso de espécies vegetais nativas de interesses apícolas;

2 - a depredação direta de enxames pela própria população que desconhece a funcionalidade ecológica das abelhas como polinizadores exímios, mesmo frente aos intensos trabalho de educação ambiental do Campus Fiocruz Mata Atlântica (CFMA), do Parque Estadual da Pedra Branca e das diversas instituições públicas de ensino superior na área, e frente aos contingenciamentos na verba da educação pública superior e fundamental sintetizados pelo atual governo federal, ter-se-á ainda menos incremento de uma educação ambiental multiplicadora na área, devido à falta de recursos para tal;

3 - em efeito Cascata a depredação dos enxames por parte da população, tem-se o ataque dos enxames depredados por forídeos, que são cleptoparasitas da ordem Diptera, pertencentes a família Phoridae, que tendem a atacar colônias de abelhas nativas que em face da depredação humana possuem pouca resiliência ambiental, para este monitoramento de abelhas, todos os enxames depredados pela população estiveram sob ataque do forídeo Pseudohypocera kerteszi, suas larvas se alimentam do pólen estocado pelas abelhas. Em casos de grandes infestações as larvas consomem totalmente os favos de crias verdes, pois eles contêm uma grande quantidade de alimento larval;

4 - a implantação da própria Transolímpica, que pelo licenciamento ambiental exigido pelos órgãos públicos, não considerou estimar o valor econômico dos recursos ambientais e 0 valor do impacto ambiental na área de influência do Corredor Viário Transolímpica, fato que se justifica devido à importância dos recursos naturais para a manutenção da vida no planeta Terra, e ao potencial que o método de Valoração Econômica de Recurso Ambiental (VERA) possui de atribuir valores monetários a esses recursos de modo que a sociedade se atente para tal importância (PEIXOTO et al., 2016). 


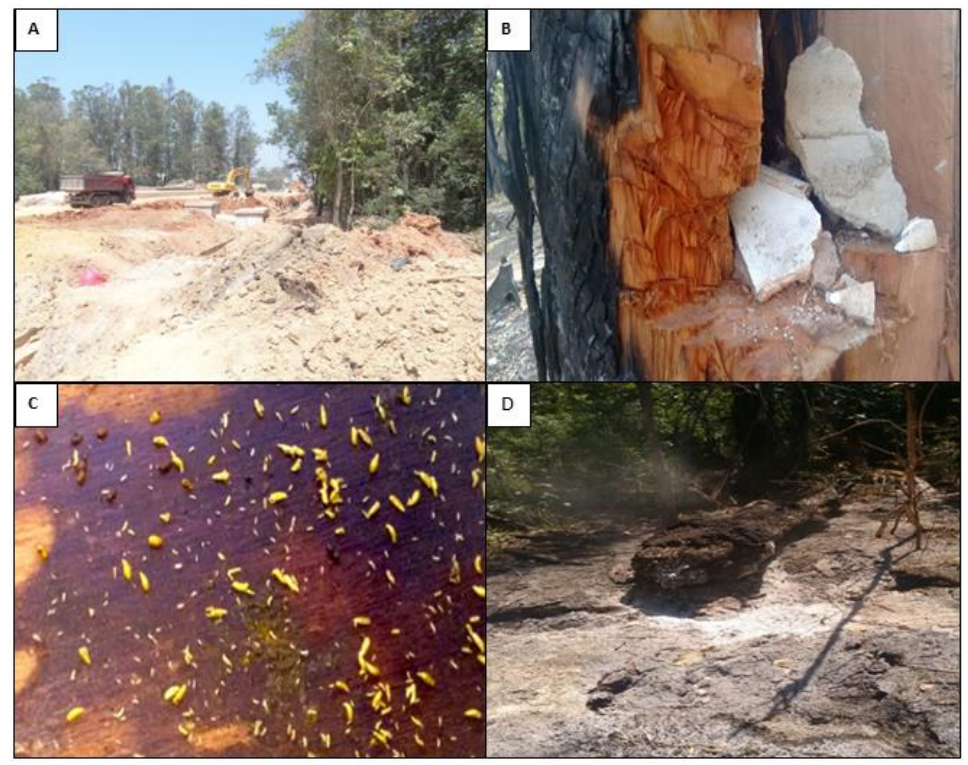

Figura 5. A- desmatamento na área de estudos; B- depredação de enxame de T. angustula; CLarvas de P. kerteszi em enxame de T. angustula; D- Afogueamento de enxame de A. mellifera. Fonte: do próprio autor.

Quanto a escolha de hábitat para a colonização e implantação de colônias a maior abundância de enxames se deteve a árvores vivas, que correspondeu a 77\% dos enxames levantados, o que é esperado devido a própria autoecologia das espécies e ao conforto ambiental, pois a madeira do ponto de vista termodinâmico possui um calor específico maior do que materiais minerais como a alvenaria das construções humanas. Quanto os demais enxames, 11 \% foram levantados em árvores mortas, $6 \%$ foram levantados em encostas de solo e $6 \%$ em construções de alvenaria.

Dos 34 enxames levantados durante o monitoramento de inverno, 28 foram mantidos na zona de amortecimento do Parque da Pedra Branca na área C9 e D9 (Figura 2), 4 enxames de $A$. mellifera foram diligenciados ao Instituto de Zootecnia da Universidade Federal Rural do Rio de Janeiro, e apenas dois enxames desta mesma espécie não sobreviveram, devido os impactos acumulados da atividade de implantação do empreendimento. Dos 46 enxames levantados durante o monitoramento de Primavera, 28 foram mantidos na zona de amortecimento do Parque Estadual da Pedra Branca, 4 enxames de A. mellifera foram diligenciados ao Instituto de Zootecnia da Universidade Federal Rural do Rio de Janeiro, 2 enxames T. angustula não sobreviveram e 12 enxames de abelhas nativas foram direcionados ao Parque da Pedra Branca para serem direcionados ao projeto de educação ambiental Trilha do Mel. Contudo, o impacto ambiental foi mitigado, uma vez que a maioria dos enxames resgatados tiveram significativa recuperação. 


\section{CONCLUSÃ0}

0 monitoramento da comunidade de abelhas na área de influência do Corredor Viário Transolímpica, inventariou significativa diversidade de abelhas nativas, reforçando que mesmo em fragmentos florestais pequenos ou impactados é possível acessar uma rica biodiversidade e uma série de serviços ecossistêmicos importantes para a sociedade e o meio ambiente.

Frente a comunidade de abelhas levantada, seria de grande importância a valoração ambiental pelo método VERA dos serviços ecossistêmicos prestados, tendo como objetivo a melhor compensação ambiental possível, sabendo-se da importância das abelhas como espécies mutualistas chave.

Com base no exposto, conclui-se que seria importante um monitoramento ambiental constante objetivado pelos órgãos públicos licenciadores, mesmo havendo a tendência de estabilização da curva de acumulação de espécies, indicando que os esforços amostrais deste trabalho foram suficientes. É possível que o ecossistema impactado tivesse ainda mais enxames de outras espécies a serem amostradas, indicando assim a conservação deste fragmento de Mata Atlântica para o bem-estar das gerações futuras e para manutenção dos atributos ecológicos do ecossistema analisado, o que é diametralmente oposto as políticas de um governo neoliberal.

\section{REFERÊNCIAS BIBLIOGRAFICAS}

ANA. AGÊNCIA NACIONAL DE ÁGUAS. Ministério do Meio Ambiente. Hidroweb: Sistemas de informações hidrológicas. 2019. Disponivel em: <http://hidroweb.ana.gov.br/>. Acesso em: 26 fev. 2020.

BRASIL. Conselho Nacional do Meio Ambiente. Resolução CONAMA no 06, de 4 de maio de 1994. Regulamenta 0 art. $6^{0}$ do Decreto $\mathrm{n}^{0} 750$, de 10 de fev. de 1993 para o Estado do Rio de Janeiro. Disponível em: < https://www.mma.gov.br/estruturas/202/_arquivos/conama_res_cons_1994_006_estgios_sucessionais_de_florest as_rj_202.pdf $>$. Acesso em: 16 fev. 2020.

BRASIL. Conselho Nacional do Meio Ambiente. Resolução CONAMA n 346, de 16 de agosto de 2004. Disciplina a utilização das abelhas silvestres nativas, bem como a implantação de meliponários. Diário Oficial [da] República Federativa do Brasil, Brasília, DF, n. 158, p. 70, ago. 2004.

BERGALLO, H. G.; ROCHA, C. F. D.; VAN SLUYS, M.; ALVES, M. A. S. 0 Status atual da fauna do Estado do Rio de Janeiro: Considerações finais. In: In: H. G. Bergallo; C. F. D. Rocha; M. A. S. Alves \& M. Van Sluys. (0rgs). A Fauna Ameaçada de Extinção do Estado do Rio de Janeiro. 1 ed. Rio de Janeiro: EDUERJ, 2000, v. 1, p. 145-150.

BERGALLO, H. G.; BERGALLO, A. C.; ROCHA, H. B; ROCHA, C. F. D. Invasion by Artocarpus heterophyllus (Moraceae) in an island in the Atlantic Forest Biome, Brazil: distribution at the landscape level, density and need for control. Journal of Coastal Conservation. v.20, n.3, p.191-198, 2016.

CASTILHOS, D. Agrotóxicos matam abelhas, diz UFERSA. Tribuna do Norte, Natal, RN, p.10-10, 2019.

CRISTO, S. C.; VITORINO, M. D.; ARENHARDT, T. C. P.; KLUNK, G. A., ADENESKY, E. F.; CARVAlHO, A. G. Leaf-litter Entomofauna as a Parameter to Evaluate Areas Under Ecological Restoration. FLORAM, v.26, p.1-11, 2019. 
Monitoramento da Comunidade de Abelhas (Hymenoptera:Apidae) na Área de Influência Direta da Via Expressa Transolímpica

FUNDAÇÃO SOS MATA ATLÂNTICA; INPE. Atlas of forest remnants of the Mata Atlântica period 2015; final report. São Paulo: The SOS. 2015.

INEA. 0 Estado do Ambiente: Indicadores Ambientais do Rio de Janeiro. Bastos, J. \& Napoleão, P. (orgs.). Rio de Janeiro: SEA, INEA, 2011.160p.

INMET. Instituto Nacional de Meteorologia. Disponivel em: $<$ Andlt;http://www.inmet.gov.br/portal/Andgt $>$. Acesso em: 24 out. 2019.

KOFFLER, S.; KLEINERT, A. M. P.. Queenless colonies of Tetragonisca angustula (Apidae: Meliponini) and the production of giant males. In: X Encontro sobre Abelhas, 2012, Ribeirão Preto.

LORENZON, M. C. A.; GARCIA, C. S.. Conservação das abelhas indígenas sem ferrão do Parque Estadual da Ilha Grande, ERJ. 0 Eco - jornal da Ilha, Abraão, Angra dos Reis, ERJ, v.47, p.13 - 13, 2003.

LORENZON, M. C. A.; Braga, J. A.; CONDE, M. M. S.; TASSINARI, W.; KOSHIYAMA, A. S. Comunidades de abelhas sujeitas às ações antrópicas em fragmentos da Mata Atlântica. REVISTA INEANA (REVISTA TÉCNICA D0 INSTITUTO ESTADUAL D0 AMBIENTE, RJ), v.6, p.55-71, 2018.

MALHEIROS, A. L.; PERAZZOLI, D. L.; VENTURA, L. M. B.; JAEN, M.. Avaliação do benefício ambiental da implantação da Trans0límpica na redução das emissões atmosféricas. REVISTA DOS TRANSPORTES PÚBLICOS, v.145, p.83-96, 2017.

MARTINS, L. C. S.; ALVARELI, L. G.; NORDI,J. C.; BARRET0,L.M. R. C.. Adequação de caixas para multiplicação de enxames e produção de mel de abelhas Melipona quadrifasciata e Melipona quadrifasciata anthidioedes. In: CONBRAPI Polinização, Tecnologia, Oportunidades e Desafios Para o Criador de Abelhas no Brasil, 2018, Joiville.

MOURA, S. G.; MURATORI, M. C. S.; MONTE, A. M.; CARNEIRO, R. M.; SOUZA, D. C.; MOURA, J. Z.. Qualidade do mel de Apis mellifera L. relacionadas às boas práticas apícolas. Revista Brasileira de Saúde e Produção Animal, v.15, p.731739, 2014.

NISHIO, E. K.; CARDOZ0, V. F.; KOBAYASHI, R. K. T.; PRONI, E. A.; FACCIONE, M.; ANDREI, C. C.; FARIA, T. J.; NAKAZATO, G.. Avaliação da Atividade Antibacteriana do Mel da Abelha Melipona Quadrifasciata quadrifasciata lepeletier (hymenoptera: apidae, meliponini. In: XXI Congresso Latinoamericano de Microbiologia (XXI ALAM), 2012, Santos.

PASIN, L. E. V.; BARRETO, L. M. R. C.; SOUZA, E. M. P.; DIB, A. P.; NORDI, J. C.. Desafios e Conquistas da Apicultura no Vale do Paraíba-SP: a Jornada dos Empreendedores Apícolas Familiares. Agricultura Familiar (UFPA), v.01, p.31-39, 2014.

PEIXOTO, D. R. S.; ALMEIDA, J. R.; SILVA, E. R.. Valoração econômica de recurso ambiental (VERA) da bacia hidrográfica de Guapi/Macacu (RJ). Revista Ibero-americana de Ciências Ambientais, v.7, p.217, 2016.

SANTOS, R. G.; CASTILHOS, D.; SOMBRA, D. S.; GRAMACH0, K. P.; GONCALVES, L. S.. SOS Abelhas: resgatando polinizadores e protegendo a comunidade. In: CONBRAPI - Congresso Brasileiro de Apicultura, 2018, Joinville.

SILVA, C.V.V.; MAGALHÃES C.. Risco Ambiental da Construção do CTR Santa Rosa Sobre o Aquífero Piranema. In: XXI Jornada de Iniciação Científica da UFRRJ, 2011, Seropédica.

SILVA, C. V. V.; ALMEIDA, J. R.; SILVA, C. E.; CARVALHO, L. 0.; SILVA, C. D.; RIGUEIRAL, L. H. G.; PAULA, R. G.. Structure and floristic survey of a forest fragment in the Billings Reservoir, São Paulo. Revista Ibero Americana de Ciências Ambientais, v.9, n.7, p.1-11, 2018.

SILVA, C. V. V.; CARVALHO, A. G.; ALMEIDA, J. R.; ABREU, L. A. S.; SILVA, K. A.; TAVARES, R.. Population Fluctuation of Coleobrocas (Coleoptera) in Six Forest Fragments in Atlantic Forest. FLORAM, v.26, p.52-70, 2019.

SILVA, C.V.V.; ABREU, L. A. S.; LEAL, J. C.; KALAOUM, J.; SILVA, S.. Levantamento da Entomofauna da APA GuanduJacatirão, Queimados-RJ e seu Uso na Avaliação Ambiental. In: XIV Congresso Nacional de Meio Ambiente, 2017, Poços de Caldas. 
TEIXEIRA, M. L. F.. Abelhas Urbanas e Sem Ferrão. Eco21, v.234, p.43, 2016.

VITORIO, C. V.; CARVAlHO, A. G.; SIlVA, K. A.; TOMAS JUNIOR, O. A.; SILVA, C. D.; LIMA, E. L. C.; ESPER, F. J.. Population Fluctuation of Termitofauna (Blattodea: Isoptera) in Six Forest Fragments of the Mata Atlântica. FLORAM, v.26, p.1$10,2019$.

WOLOWSKI, M.; NUNES, C. E. P.; AMORIM, F.; VIZENTIN-BUGONI, J.; AXIMOF, I.; MARUYAMA, P. K.; BRITO, V. L. G.; FREITAS, L.. Interações Planta-polinizador Em Vegetação De Altitude Na Mata Atlântica. OECOLOGIA AUSTRALIS, v.20, p.7-23, 2016. 